\section{Leather-Jacket Control with Benzene Hexachloride}

\section{and with D.D.T.}

THE leather-jacket is a serious pest in fine turf culture and annually takes toll of considerable acreages. In the past the chief methods of control have involved the use of lead arsenate or an emulsion of orthodichlorobenzene. Lead arsenate is costly while the orthodichlorobenzene emulsion is not lethal and its use involves the necessity of sweeping the anæsthetized grubs from the surface. The possibilities of the new insecticides D.D.T. and 'Gammexane' have

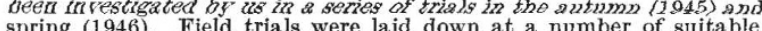
spring (1946). Field trials were laid down at a number of suitable results obtained has come from practical tests carried out throughout results obtained has
the British Isles.

Using a replicated random block lay-out on areas of turf known to be infected, various rates of both D.D.T. and 'Gammexane' were tested. The living leather-jacket population at all relevant times was measured by counting the leather-jackets which could be brought to the surface by means of orthodichlorobenzene emulsion within a 6 -in. sq. frame, by means of orthodichlorobenzene emulsion within a 6-in. Sq. frame, making nine random throws on each experimental plot. The original population varied from as few as 50 per sq. yd. at one centre (where little damage was evident) to well over 1,000 per sq. yd. at another
(where the turf was being seriously damaged). Satisfactory results (where the turf was being seriously damaged). Satisfactory results were obtained in one to three weeks from application

or 'Gammexane' at very low rates of application.
Using certain commercial 5 per cent D.D.T. powders, 100 per cent control could be obtained from $\frac{1}{2}$ oz. per sq. yd., which represents only $0.025 \mathrm{oz}$. commercial D.D. T. per sq. yd. or about $0.02 \mathrm{oz}$. of the pure para para compound. Even lower rates of D.D.T. application were required when a 5 per cent emulsion was used. One gallon of such emulsion diluted with water to 400 gallons proved sufficient to give complete control over 800 sq. yd. of infected turf. This rat is equivalent to only $0.01 \mathrm{oz}$. of commercially pure D.D.T. per sq. yd. 'Gammexane' was tested in the form of powders containing $3 \frac{1}{2}$ per cent and 5 per cent benzene hexachloride, of which 13 per cent is actually gamma isomer. A suitable rate of application for complete control proved to be the equivalent of $1 \mathrm{oz}$. of the $3 \frac{1}{2}$ per cent formula tion per sq. yd. This provide.

A liquid preparation of benzene hexachloride was not available to us in time for the trials. It is proposed to test this and a furthe number of D.D.T. preparations (including pastes and wettable powders) this autumn. At the same time it is hoped to find out whether from last season's treatments there are any residual effects on this season's broods of leather-jackets.

A fuller account of this work will be published in the next issue of the Journal of the Board of Greenkeeping Research.

Board of Greenkeeping Research,

St. Ives Research Station,

Bingley, Yorkshire.

Aug. 22.

Modern Insecticides and their Use against Wireworms

No chemical means of wireworm control have so far been effective and the farmer's only means of combating the ravages of this pest have been cultural.

In view, therefore, of the potentialities of the new insecticides, D.D.T and 'Gammexane', in this connexion, simple laboratory experiment were designed to investigate their possibilities.

Wooden boxes of known area were filled with soil and a definite number of wireworms (Agriotes obscurus) introduced into each. The population (wireworms in 1,000's per acre) was thus known. Before
introduction the wireworms were graded in size, so that the potential introduction the wireworms were graded in

A series of eight boxes, in four pairs, was used, boxes Nos. 2, 4, 6 and 8 being untreated controls, while Nos. $1,3,5$ and 7 were treated as follows :

Box No.

1. 'Gammexane', 2 cwt. per acre, broadeast.

3. D.D.T. (Guesarol E.C. 5 per cent), 1 cwt. per acre, broadcast.

5. 'Gammexane', 1 cwt. per acre, 1 cwt. per acre, drilled with

7. D.D.T. (Guesarol E.C. 5 per cent), $\frac{3}{2}$ cwt. per acre, drilled with seed.

In the case of boxes Nos. 1 and 3 , the insecticide was evenly broadcast over the surface and lightly raked in, while in boxes Nos. 5 and 7 it was evenly placed along the bottom of two ' $V$-shaped' furrows, $1 \mathrm{in}$. deep and 5 in. apart, running along the length of the box.

Spring oats, previously soaked until germination had begun, were then sown at the rate of $1,500,000$ seeds per acre, being placed in two drills 1 in. deep and 5 in. apart (in boxes Nos. 5 and 7 the seeds were placed in the previously prepared furrows directly on top of the D.D.T. and 'Gammexane') and covered with soil.

It should be pointed out that conditions were in favour of wireworm attack, no manurial treatment being given to assist the plants to 'grow away' and no consolidation and preparation of a good seed bed taking place. Also the fact that the seeds had germinated before sowing ensured that they were all viable.

All boxes were then placed outside and examined daily to determine (1) the number of plants which successfully appeared above the surface ; (2) the number of plants afterwards attacked.

After nineteen weeks, the oats from each box were threshed, the After nineteen weeks, the oats from each box were threshed, the
yield weighed and the soil examined to determine wireworm mortality. The results, which it is hoped to publish in detail later when parallel field trials have been completed, are of much interest and show deflnite beneflcial effects from the use of D.D.T. and 'Gammexane'

Briefly; they are as follows :
Box No.

1. 'Gammexane' broadcast 2. Control

4. D.D.T.

Regarding wireworm mortality, all those recovered from the controls were normal, healthy and active, while those from the treated boxes, severa 2 of which wore dead, wero slugsish and apporeptly-
unable to control their movements. In view of previous observations on wireworms after D.D.T. and 'Gammexane' treatment (unpub.), it was considered that none would recover and therefore mortality was classifled as 100 per cent as against none in the controls.

Boxes Nos. 5, 6, 7 and 8 generally did not give such definite results because for some unknown reason wireworm attack did not occur on any scale even in the controls. However, here again, on examining the soil, the mortality' was much higher in the treated boxes, although some (up to 14 per cent) did occur in the controls.

Therefore, although the above conditions are somewhat artificial and from them field deductions cannot be definitely made, it appears that with further investigations using these insecticides, the answer to the wireworm menace may be in sight.

$$
\begin{gathered}
\text { Department of Agriculture, } \\
\text { King's College, } \\
\text { Newcastle-upon-Tyne. } \\
\text { Aug. } 28 .
\end{gathered}
$$

W. H. GolightLY

\section{Kinetics of Aromatic Nitration: the Nitronium lon}

MARTINSEN (1904) first obtained a definite kinetic order for the nitration of aromatic substances. His solvent was sulphuric acid, and his demonstration ${ }^{1}$ of second-order kinetics in this medium has since been fully confirmed ${ }^{2,3}$ :

Rate $=k_{2}[\mathrm{ArH}]\left[\mathrm{HNO}_{3}\right] \quad\left(\right.$ in $\left.\mathrm{H}_{2} \mathrm{SO}_{4}\right)$

Benford and Ingold obtained the first well-defined kinetic results in any solvent other than sulphuric acid. With nitromethane as solvent, and nitric acid in constant excess, they demonstrated zerothorder kinetics ${ }^{4}$ :

Rate $=k_{0} \quad$ (in organic solvents, $\left[\mathrm{HNO}_{3}\right]=$ const. $)$

This insensitiveness of the rate to the concentration and nature of the aromatic compound applied only to relatively reactive compounds, such as benzene and toluene. With less reactive compounds, such as chlorobenzene, some dependence of the rate on the compound was observed. We have continued these experiments, and, for considerably less reactive compounds, such as $p$-dichlorobenzene and ethyl benzoate, have established first-order kinetics:

$$
\text { Rate }=k_{1}[\mathrm{ArH}] \quad \text { (in organic solvents, }\left[\mathrm{HNO}_{3}\right]=\text { const.) }
$$

Benford and Ingold thought that their results were peculiar to nitromethane, but we have observed all the same phenomena with acetic acid as solvent.

This change of kinetic order clearly has the same importance for This change of kinetic order clearly has the same importance for
aromatic nitration as the similar discovery for alkyl halide reactions had for the mechanism of nucleophilic aliphatic substitution. Just as alkyl halides (or alcohols in acid media) may undergo a rateas alkyl halides (or alcohols in acid media) may undergo a ratea heterolysis, which may be rate-determining if the formed nitronium ion is sufficiently rapidly removed by the aromatic compound. (It ion is sufficiently rapidly removed by the aromatic compound. (It organic and inorganic reagents possess interchanged functions, aromatic nitration being an electrophilic substitution.) A slow heterolysis of nitration being an electrophilic substitution.) A slow heterolysis of
nitric acid cannot depend only on proton transfers, and therefore the nitric acid cannot depend only on proton transfers, and therefore the occur in an NO-bond, the only plausible interpretation being

$$
\mathrm{O}_{2} \mathrm{~N}-\mathrm{OH} \rightarrow \mathrm{O}_{2} \mathrm{~N}++\mathrm{OH}-
$$

The actual mechanism is considered to involve a preliminary proton uptake (as in the formation of carbonium ions from alcohols in acid media). The details differ according as the medium is more or less strongly acidic than nitric acid. Thus in sulphuric acid we assume

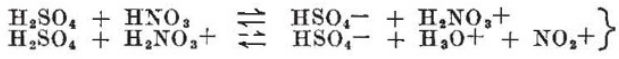

and in organic solvents,

$$
\left.\underset{\mathrm{H}_{2} \mathrm{NO}_{3}}{2 \mathrm{HO}_{3}} \underset{\mathrm{NO}_{2} \mathrm{O}}{\stackrel{\mathrm{N}_{3}}{\rightleftarrows}+\underset{\mathrm{NO}_{2}}{\mathrm{H}}+\mathrm{H}_{3}+}\right\}
$$

We have observed a strong acceleration on the addition, in organic solvents, of an acid (for example, $\mathrm{H}_{2} \mathrm{SO}_{4}$ ) stronger than nitric acid, the catalysed reaction still showing zeroth-order kinetics under suitable conditions.

Euler (1922) first envisaged the nitronium ion, $\mathrm{NO}_{2}+$, as a nitrating entity ${ }^{5}$ and the idea has since been frequently supported ${ }^{6,3}$. Our deduction 7 alike of the formation and effectiveness of $\mathrm{NO}^{2}+$ from the change of kinetic order on nitration seems particularly certain
and direct. Since an independent species is needed to remove the aromatic proton, the rate equation for the nitration mechanism may be written

$$
\text { Rate }=k[\mathrm{ArH}]\left[\mathrm{NO}_{2}+\right][\text { Base }]
$$

